\title{
Food shopping at supermarkets and hypermarkets and diet quality in Greater Tunis
}

\author{
S. Tessier ${ }^{1}$, P. Traissac ${ }^{1}$, B. Maire ${ }^{1}$, N. Bricas ${ }^{2}$, S. Eymard-Duvernay ${ }^{1}$, J. El Ati ${ }^{3}$ and F. Delpeuch ${ }^{1}$ \\ ${ }^{1}$ IRD UR 106 'Nutrition Alimentation Sociétés', Montpellier, France, ${ }^{2}$ CIRAD UR 'Normes et Régulation des Marchés \\ Agricoles', Montpellier, France and ${ }^{3}$ INNTA, Tunis, Tunisia
}

There has been a recent, but nonetheless rapid, spread of large food retail outlets (LFR) in low-income Mediterranean countries such as Morocco, Tunisia and most recently Algeria. It is also predicted to accelerate in the near future. In the context of rising obesity and CVD prevalence in these countries, it is not known whether food retail changes have an impact on diet quality and if it is beneficial or detrimental to health. Thus, the present study has assessed food shopping at LFR, the socio-economic determinants and its effect on diet quality in Tunisia.

The target population was all 25-70 year olds living in the Greater Tunis area where LFR are mostly located. The 724 subjects interviewed were selected by three-stage clustered random sampling. Retail habits were assessed by a purposely-developed quantitative questionnaire derived from face-to-face interviews and focus groups. Socio-economic data were collected at both individual and household levels. Diet quality was measured using the diet quality index international (DQII ${ }^{(1)}$ ) derived from an FFQ specific for Tunisia. Data analysis, using multiple regression or logistic regression models, was twofold: (a) assessing food shopping at LFR (i.e. proportion and profiles of LFR consumers $v$. none), (b) assessing the relationship between diet quality and shopping at LFR, adjusted for socio-economic confounders when relevant.

Overall, $60 \%$ of the subjects surveyed shopped at LFR, of whom half $(51 \%)$ shopped at supermarkets and only approximately onequarter $(27 \%)$ shopped at hypermarkets. A total of $32 \%$ shopped at supermarkets only, whereas $18 \%$ shopped exclusively at hypermarkets. Most of the subjects (94\%) still used the local grocer, whereas only $26 \%$ shopped at the market. Overall, it was found that those shopping at LFR were more likely to be from small-size households (OR 2.2; $P=0.01)$, lived in an urban area $(\mathrm{OR} 3.7 ; P=0.01)$, had greater educational attainment (OR 5.7; $P<0.0001)$, had a high economic level (OR $4.1 ; P<0.00001)$ or a steady income $(\mathrm{OR} 2.0$; $P=0.01)$ or had easy access to the LFR (OR 2.0; $P=0.04$ ). Similar but stronger relationships were found for the $20 \%$ of subjects who shopped at LFR as a first choice. After adjustment, a slightly higher DQII was only significantly associated with shopping at LFR as a first choice $v$. others (score 63 v. 59; $P=0.0004$ ).

These results therefore show that despite the longstanding presence of supermarkets in Tunis, shopping at LFR is not yet generalised to the whole population. LFR have not had a major modifying effect on food consumption among the Greater Tunis population. However, a slight improvement in diet quality can be observed among those who regularly shop at LFR.

1. Kim S, Haines PS, Siega-Riz AM \& Popkin BM (2003) J Nutr 133, 3476-3484. 